\title{
Ultrathin Oxide Passivation Layer by Rapid Thermal Oxidation for the Silicon Heterojunction Solar Cell Applications
}

\author{
Youngseok Lee, ${ }^{1}$ Woongkyo Oh, ${ }^{2}$ Vinh Ai Dao, ${ }^{2,3}$ Shahzada Qamar Hussain, ${ }^{1}$ and Junsin Yi ${ }^{1,2}$ \\ ${ }^{1}$ Department of Energy Science, Sungkyunkwan University, Suwon 440-746, Republic of Korea \\ ${ }^{2}$ School of Information and Communication Engineering, Sungkyunkwan University, Suwon 440-746, Suwon, Republic of Korea \\ ${ }^{3}$ College of Science, Faculty of Material Science, Vietnam National University, 227 Nguyen Van Cu, Hochiminh, Vietnam
}

Correspondence should be addressed to Junsin Yi, yi@yurim.skku.ac.kr

Received 16 November 2011; Accepted 27 December 2011

Academic Editor: Bhushan Sopori

Copyright (C) 2012 Youngseok Lee et al. This is an open access article distributed under the Creative Commons Attribution License, which permits unrestricted use, distribution, and reproduction in any medium, provided the original work is properly cited.

\begin{abstract}
It is difficult to deposit extremely thin a-Si:H layer in heterojunction with intrinsic thin layer (HIT) solar cell due to thermal damage and tough process control. This study aims to understand oxide passivation mechanism of silicon surface using rapid thermal oxidation (RTO) process by examining surface effective lifetime and surface recombination velocity. The presence of thin insulating a-Si:H layer is the key to get high $V_{\text {oc }}$ by lowering the leakage current $\left(I_{0}\right)$ which improves the efficiency of HIT solar cell. The ultrathin thermal passivation silicon oxide $\left(\mathrm{SiO}_{2}\right)$ layer was deposited by RTO system in the temperature range $500-950^{\circ} \mathrm{C}$ for 2 to 6 minutes. The thickness of the silicon oxide layer was affected by RTO annealing temperature and treatment time. The best value of surface recombination velocity was recorded for the sample treated at a temperature of $850^{\circ} \mathrm{C}$ for 6 minutes at $\mathrm{O}_{2}$ flow rate of $3 \mathrm{Lpm}$. A surface recombination velocity below $25 \mathrm{~cm} / \mathrm{s}$ was obtained for the silicon oxide layer of $4 \mathrm{~nm}$ thickness. This ultrathin $\mathrm{SiO}_{2}$ layer was employed for the fabrication of HIT solar cell structure instead of a-Si:H, (i) layer and the passivation and tunneling effects of the silicon oxide layer were exploited. The photocurrent was decreased with the increase of illumination intensity and $\mathrm{SiO}_{2}$ thickness.
\end{abstract}

\section{Introduction}

The surface passivation effect is one of the most important characteristics in the fabrication of solar cells $[1,2]$. The decrease in quality of surface passivation limits the efficiency of solar cell due to increase of surface recombination velocity $\left(S_{\text {eff }}\right)$. An increase in surface recombination reduces the generation of electron hole pair (EHP). The quality of the silicon wafer is also a decisive factor to get high-efficiency solar cell. One of the typical features that decide the quality of a wafer is its diffusion length. The diffusion length of a wafer can be correlated with its diffusivity and surface passivation. The typical passivation layers used are $\mathrm{SiO}_{2}$ and silicon nitride $\left(\mathrm{SiN}_{x}\right)$ thin films. The passivated emitter, rear locally diffused (PERL) cell and heterojunction with intrinsic thin layer (HIT) solar cell recorded an efficiency of $23 \%$ and $24.7 \%$, respectively $[1,2]$. The PERL cell utilized $\mathrm{SiO}_{2}$ as the passivation layer whereas a-Si:H(i) is used as passivated layer in HIT solar cell to obtain an efficiency of over $20 \%$.
S. De Wolf et al. [3] indicated that a-Si:H layer is thermally unstable. However, $\mathrm{SiO}_{2}$ will be an appropriate passivation layer for the solar cell fabrication due to its thermal stability and low interface defect density $\left(D_{\text {it }}\right)$ [4]. The oxidized ntype silicon has a much better surface passivation properties than p-type silicon due to the small hall capture cross-section ( $\sigma_{n} / \sigma_{p} \approx 1000$ at mid gap) [5] and optimized thermal oxide interface state densities of the order of $10^{9}$ to $10^{10} \mathrm{~cm}^{-2} \mathrm{eV}^{-1}$ range $[5,6]$. Two different mechanisms leading to good passivation are (i) the reduction of interface defect states and (ii) the field effect passivation, that is, the high reduction of one type of carrier by the incorporation of fixed charges $Q_{f}$ in the passivation layer [7]. A reduction of interface state together with the field effect passivation is more effectively expected to attain for thermally grown $\mathrm{SiO}_{2}$ layers $[8,9]$.

This thermal oxide growth could be achieved by two different methods. One is by the normal conventional furnace process (CFO) and the other is by the rapid thermal oxidation (RTO) process. The CFO process has 
few disadvantages such as low throughput, high process cost, and high thermal budget. On the other hand RTO process is driven by the necessity to reduce the overall thermal budget associated with device fabrication and in particular to maintain the desired device electrical properties [10].

In this study, we used a thermal oxide process (RTO process) for the growth of the $\mathrm{SiO}_{2}$ as a passivation layer for the HIT solar cell application and discussed $\mathrm{SiO}_{2}$ layer's passivation property.

\section{Experimental Method}

2.1. Thermal Oxide Passivation Process. The n-type polished crystalline (100) silicon substrates having a resistivity of 2$3 \Omega-\mathrm{cm}$ were used for this study. The resistivity of the silicon substrate has a decisive effect on the growth rate of $\mathrm{SiO}_{2}$. The substrates were cut into $20 \mathrm{~cm}^{2}$ pieces and were ultrasonically cleaned in sequence by dipping in acetone, isopropyl alcohol, and deionized (DI) water for 10 minutes. The native oxide layer was removed by dipping the substrate in $2 \% \mathrm{HF}$ for 2 minutes. Rapid thermal oxidation technique using infrared (IR) lamp was utilized to oxidize the silicon substrates. The oxygen flow rate and temperature were varied in the range of $1-8 \mathrm{Lpm}$ and $500-950^{\circ} \mathrm{C}$, respectively. Firstly, the chamber was filled with nitrogen gas. At the steady state temperature, only oxygen was passed through the chamber. Lifetime was measured by photoconductive decay (PCD, WCT-1200) model. We confirmed the surface passivation effect of $\mathrm{SiO}_{2}$ layer and estimated the surface recombination velocity (SRV) using PCD. The thickness of the $\mathrm{SiO}_{2}$ layer formed by RTO process was measured by Ellipsometry (VB250, J. A. Woollam) system. The metal-oxide-semiconductor (MOS) structure was fabricated to measure the interface trap density $\left(D_{\text {it }}\right)$. The $D_{\text {it }}$ value of the MOS structure was calculated by $C-V$ measurement (HP-4129A) at $1 \mathrm{MHz}$.

2.2. Heterojunction Fabrication Process. The HIT solar cell structure was fabricated after growing an ultrathin $\mathrm{SiO}_{2}$ layer on the silicon substrate by the RTO process. A ptype hydrogenated amorphous silicon $(\mathrm{a}-\mathrm{Si}: \mathrm{H}(\mathrm{p}))$ layer was deposited as an emitter on the polished side of the n-type Czochralski (CZ) silicon substrate and n-type hydrogenated amorphous silicon (a-Si:H(n)) layer was deposited as back surface field (BSF) layer on the rear side of the n-type CZ wafer. The thickness of the $\mathrm{SiO}_{2}$ layer was around $3 \mathrm{~nm}$. The thickness of the a-Si:H( $\left(\mathrm{p}^{+}\right)$and a-Si: $\mathrm{H}\left(\mathrm{n}^{+}\right)$layers was kept fixed at $7 \mathrm{~nm}$ and $10 \mathrm{~nm}$, respectively. The deposition of ITO was performed by magnetron sputtering using a metal mask that was directly placed on the a-Si:H(p) surface. The evaporation method was used to deposit $\mathrm{Ag} / \mathrm{Al}$ electrodes $(200 \mathrm{~nm})$ on the ITO and rear side to enable a good ohmic contact. The reactive ion etching (RIE) was carried out using $\mathrm{SF}_{6}$ gas on the top side for mesa-etching. Finally, the above sample was annealed in air, and the solar cell characteristics have been measured.

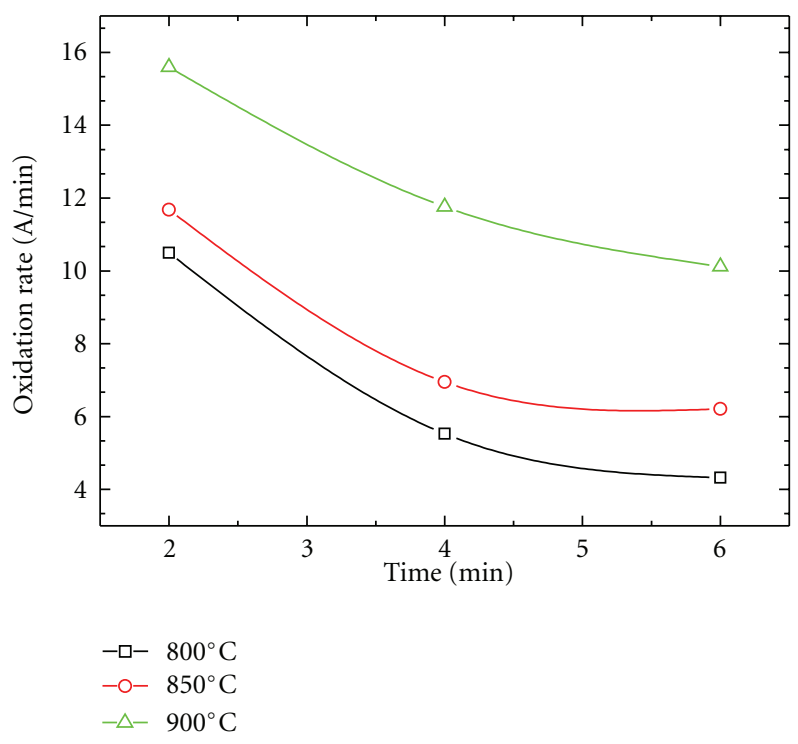

FIgURE 1: Oxidation rate of silicon substrate during rapid thermal annealing process at 800,850 , and $900^{\circ} \mathrm{C}$ with time.

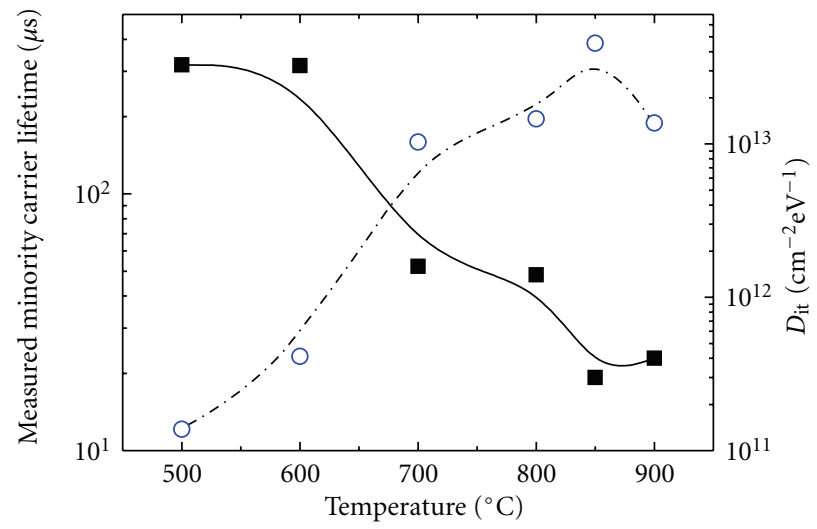

FIGURE 2: Variation of effective lifetime and interface trap density $\left(D_{\text {it }}\right)$ as a function of rapid thermal annealing temperature.

\section{Results and Discussion}

Figure 1 depicts variations in the oxidation rate of silicon substrate during the rapid thermal annealing process at 800 , 850 , and $900^{\circ} \mathrm{C}$ as a function of time. The variation of the oxidation rate as a function of time can be explained by modifying the Deal-Grove model, which is accurate for very thin layer up to $1 \mathrm{~nm}$, and proposed by Watanabe et al. [11]. Based on the Watanabe formulas, the thickness of the film as function of time can be expressed in the following form:

$$
\frac{d}{d x_{0}}\left(\frac{d t}{d x_{0}}\right)=\frac{N_{1}}{D_{0} C^{*}}-\frac{N_{1}}{2 D_{0}^{2} C^{*}}\left(A+2 x_{0}\right) \frac{d D_{0}}{d x_{0}},
$$

where the second term on the right side corresponds to the deviation from the linear kinetics of $d t / d x_{0}$. If $d D / d x_{0}>0$; that is, $D_{0}$ is decreased as $x_{0}$ decreases, the slope of $d t / d x_{0}$ decreases. In this case, the plot bends upward at the thin oxide region (short annealing time), as shown in our 


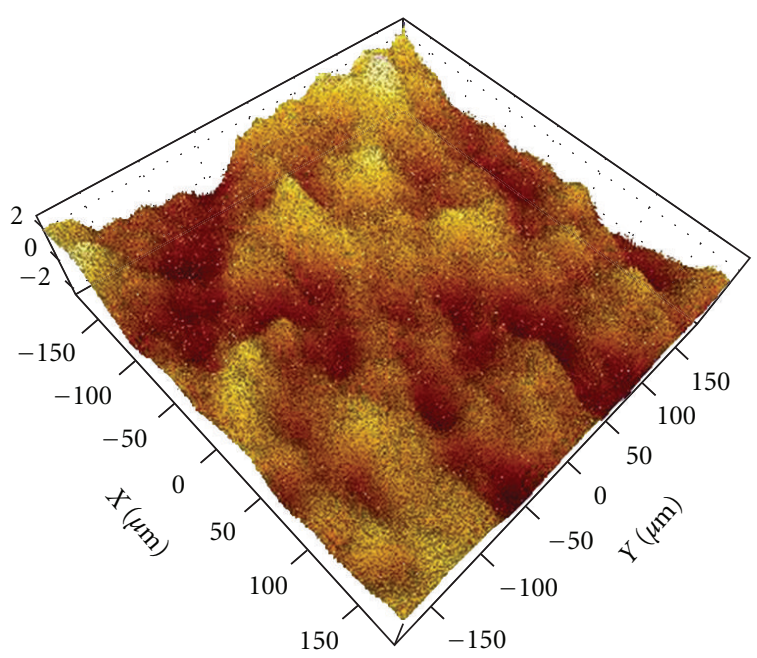

(a) $0.796 \mathrm{~nm}$

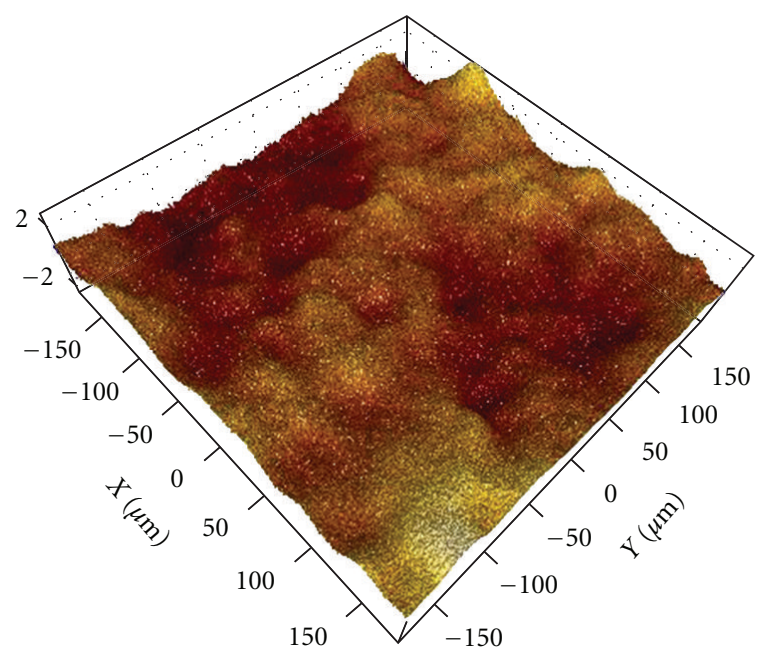

(c) $1.07 \mathrm{~nm}$

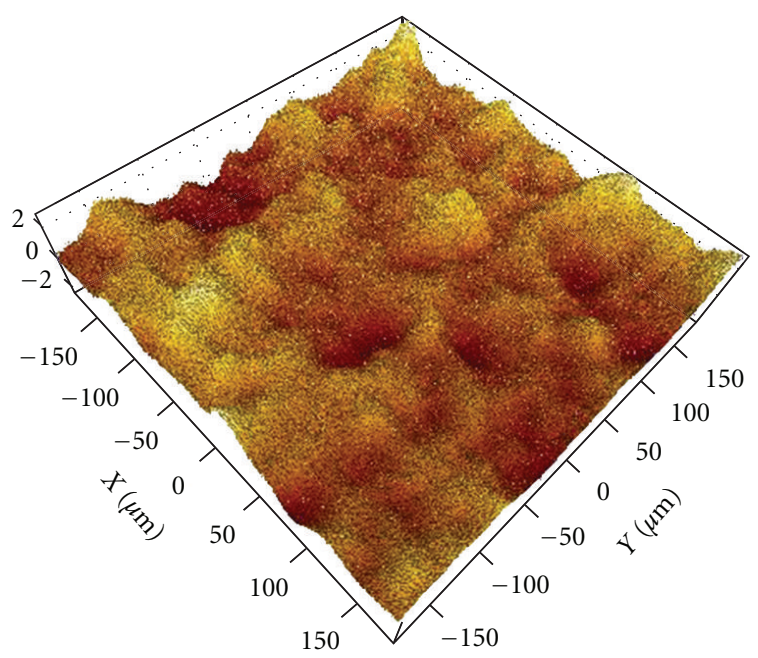

(b) $0.703 \mathrm{~nm}$

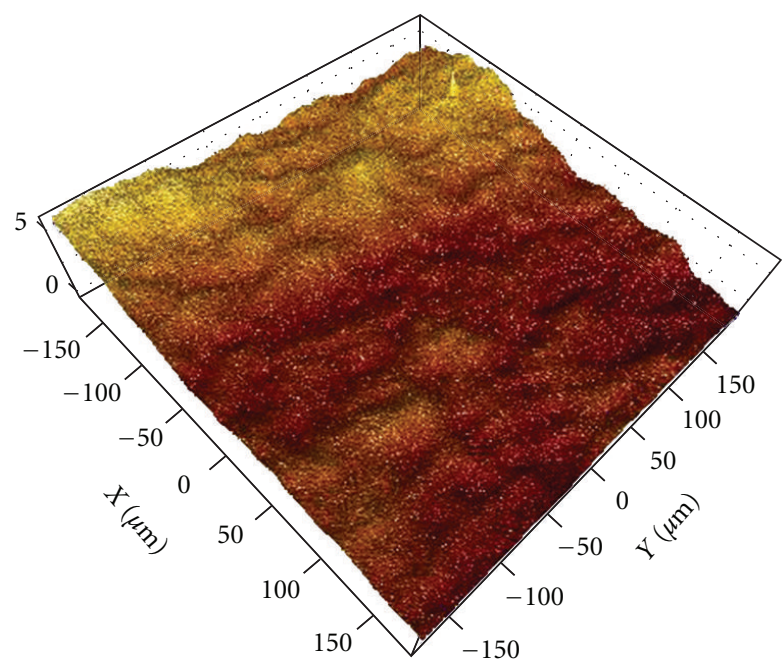

(d) $1.98 \mathrm{~nm}$

FIGURE 3: RMS as a function of rapid thermal annealing temperature: (a) 750, (b) 850, (c) 900, and (d) $950^{\circ} \mathrm{C}$.

experiment results. Thus, it can be seen from the figure that the oxidation rate depends on the rapid thermal annealing temperature and shows a similar trend in the variation irrespective of RTO temperature. However, as the RTO temperature increased from 800 to $900^{\circ} \mathrm{C}$, the $\mathrm{SiO}_{2}$ layer formation rate was higher, as expected.

Figure 2 shows the variation in the effective lifetime and interface trap density $\left(D_{\text {it }}\right)$ of the HIT solar cell as a function of RTA temperature. According to (1), an increase in effective life time would reduce the surface recombination velocity of the structure. When the thermal annealing temperature increased, the defect content of the surface may decrease that would reduce the surface recombination of carriers and result in an increase of effective carrier life time. The figure also shows that the effective lifetime increased when the temperature was increased from 500 to $850^{\circ} \mathrm{C}$, maximum being at $850^{\circ} \mathrm{C}$. As expected, the interface trap density $\left(D_{\text {it }}\right)$ decreased with an increase of RTO annealing temperature, implying that the surface passivation quality is enhanced with an increase of temperature. The $D_{\text {it }}$ gives a measure of the defects at the interface between Si substrate and $\mathrm{SiO}_{2}$ layers. In order to explain the tendency of $D_{\mathrm{it}}$, the surface roughness of the $\mathrm{SiO}_{2} / \mathrm{c}$-Si was estimated at different annealing temperatures, that is, $750,850,900$ and $950^{\circ} \mathrm{C}$, as shown in Figure 3. From Figure 3, we can deduce the average interface nanoroughness affects the interface condition $\left(D_{\text {it }}\right)$. As the average interface nanoroughness gets bigger, however, the $\tau_{\text {eff }}$ decreased. It is also revealed that the lowest $D_{\text {it }}$ as well as nanoroughness simultaneously can be observed. This is considered because the carriers are scattered by nanoroughness of the $\mathrm{Si} / \mathrm{SiO}_{2}$ interface [12]. Therefore it will become of more importance to improve the smoothness of $\mathrm{Si} / \mathrm{SiO}_{2}$ interface.

The illuminated current-voltage $(I-V)$ characteristics of the device at different light intensity sources are shown in Figure 4 along with the dark $I-V$ characteristics measured at 


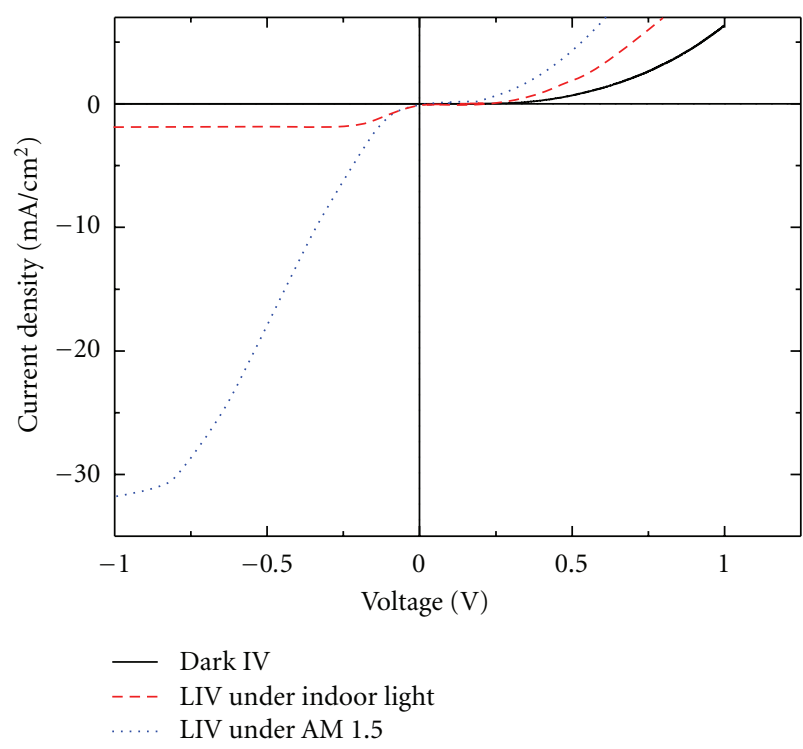

FIgURE 4: The illuminated current-voltage $(I-V)$ characteristics of the device at different light intensity sources.

room temperature. It is observed from the figure that the illuminated $I-V$ curve has been distorted (S-shaped) and the dark $I-V$ curve retain in its original form. A change in light intensity results in changing of output current density, but does not change the shape of the photo $I-V$ curve. We performed numerical simulation using AFORS-HET to determine the probable cause of the S-shaped $I-V$ curve. The simulation results are shown in Figures 5(a) and 5(b). Figure 5(a) shows the change in illuminated $I-V$ curve with increasing energy bandgap. When we increased the energy bandgap from 1.72 to $1.89 \mathrm{eV}$, the illuminated $I-V$ shape changed toward our experimental results. Figure 5(b) shows the band diagram of the device having different valence band offset. From band diagram we may assume that higher bandgap of the buffer intrinsic oxide results in higher band offset, lowering electron affinity, and opposes the flow of the photocurrent in the device.

In order to remove the S-shaped curve in the $I-V$ characteristics, both our simulation and van Cleef's experiment [13] suggested that (1) the energy band gap is either lower than $1.72 \mathrm{eV}$ or (2) enhances the tunneling mechanism at the interface which mitigate the blocking of photo-generated free holes by a high valence band discontinuity. It is well known that $\mathrm{SiO}_{2}$ is a wide-band-gap material $(>4.0 \mathrm{eV})$ if it is grown by RTO method. Figure 6 shows the $I-V$ characteristics of our device as a function of the intrinsic $\mathrm{SiO}_{2}$ thickness in range of 1.0-3.4 $\mathrm{nm}$. The S-shaped curve in $I-V$ characteristics can be significantly reduced or even completely removed with the reduction of thickness. It is clear that the decrease thickness of the $\mathrm{SiO}_{2}$ in the results in a narrow valence band spike. Then photogenerated holes are able to tunneling through the $\mathrm{SiO}_{2}$ layer. Consequently a high accumulation of holes at the interface is prevented, and, also depletion region is prevented from spreading too much inside the emitter. At the same time, the $\mathrm{SiO}_{2}$ layer's band gap is too high for the

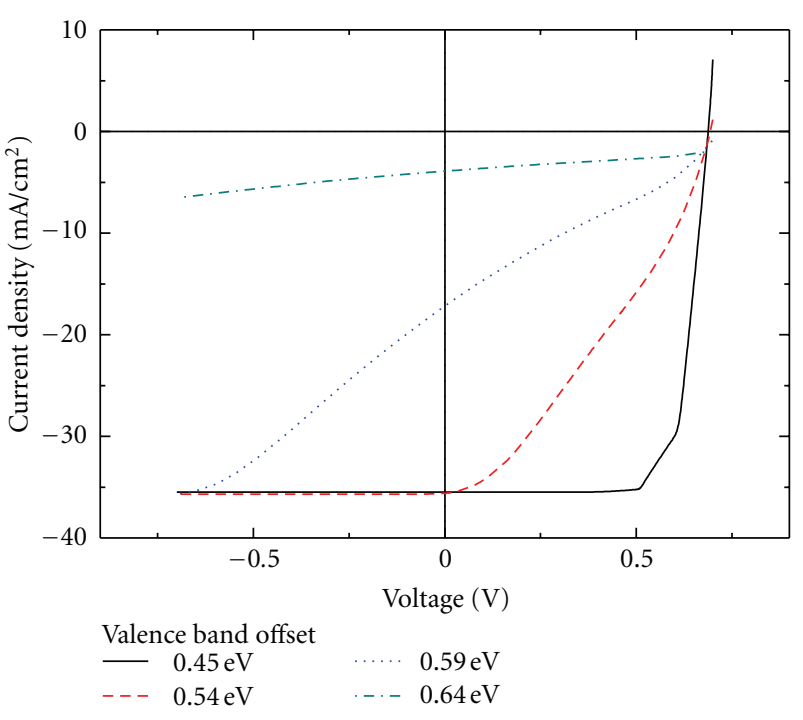

(a)

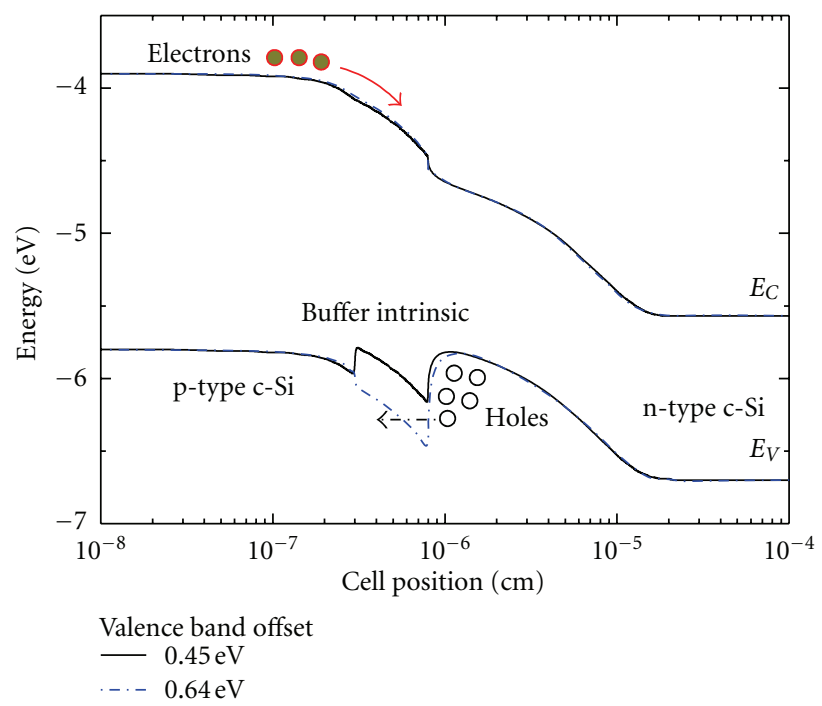

(b)

Figure 5: (a) Simulated $I-V$ curve with different energy band gap of passivation layer, (b) schematic of the band diagram depend on energy band gap of passivation layer.

photoelectrons to cross the tunneling layer. When we apply wide-band-gap material to passivation layer in HIT solar cell structure, we should consider compromising condition between band gap and thickness.

\section{Conclusion}

The surface passivation is very important issue in amorphous and crystalline silicon solar cell applications as it highly influenced the performance of the device. Here we used ultrathin thermal passivation $\mathrm{SiO}_{2}$ layer deposited by RTO system as a function of temperature and time for the fabrication of HIT solar cell. The high RTO annealing temperature can decrease the surface defects and reduce the 


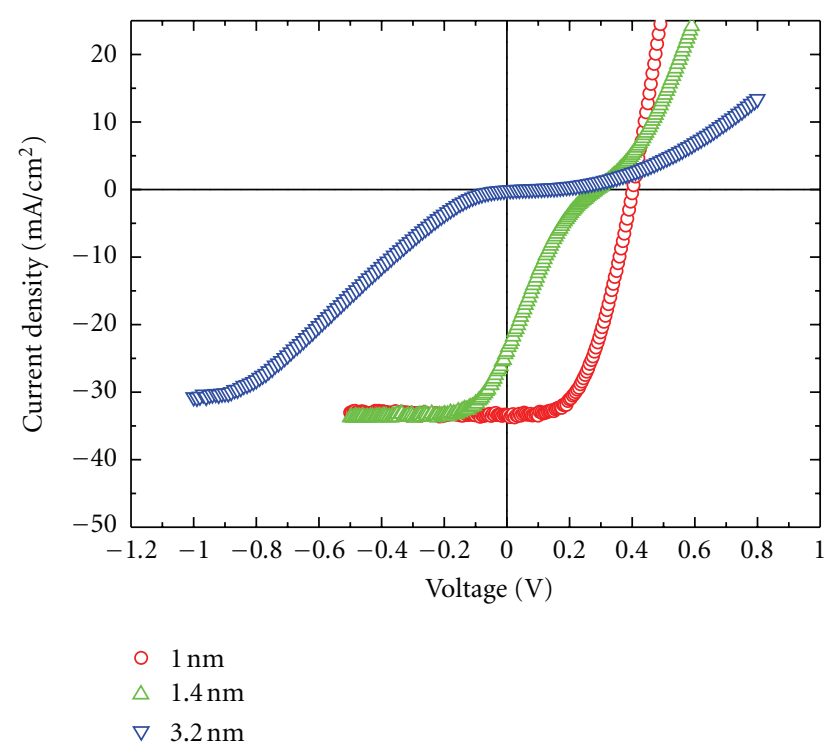

FIGURE 6: Variation of current density as a function of voltage of silicon oxide layer with thicknesses $1,1.4$, and $3.2 \mathrm{~nm}$ formed by rapid thermal annealing process.

surface recombination which caused an increase in effective life time. The $\mathrm{SiO}_{2}$ layer deposited at a temperature of $850^{\circ} \mathrm{C}$ for 6 minutes gives the best values of $S_{\text {eff, although the }}$ performance of our fabricated HIT solar cell using $\mathrm{SiO}_{2}$ passivation layer is not better than the conventional HIT solar cell using a-Si:H(i) as a passivation layer. The bandgap is also a key factor to use $\mathrm{SiO}_{2}$ as a passivation layer, which is yet to be tried to achieve for the upcoming experiments. The $\mathrm{SiO}_{2}$ passivation layer can be employed in HIT solar cell by proper control of bandgap and tunnelling mechanism.

\section{Acknowledgments}

This research was supported by WCU (World Class University) program through the National Research Foundation of Korea funded by the Ministry of Education, Science and Technology (R31-2008-000-10029-0).

\section{References}

[1] J. Zhao, A. Wang, and M. A. Green, " $24.5 \%$ efficiency silicon PERT cells on MCZ substrates and $24.7 \%$ efficiency PERL cells on FZ substrates," Progress in Photovoltaics, vol. 7, no. 6, pp. 471-474, 1999.

[2] T. Mishima, M. Taguchi, H. Sakata, and E. Maruyama, "Development status of high-efficiency HIT solar cells," Solar Energy Materials and Solar Cells, vol. 95, no. 1, pp. 18-21, 2011.

[3] S. De Wolf and M. Kondo, "Boron-doped a-Si:Hc-Si interface passivation: degradation mechanism," Applied Physics Letters, vol. 91, no. 11, Article ID 112109, 3 pages, 2007.

[4] S. W. Glunz, "High-efficiency crystalline silicon solar cells," Advances in Optoelectronics, vol. 2007, Article ID 97370, pp. $1-15,2007$.

[5] A. G. Aberle, "Surface passivation of crystalline silicon solar cells: a review," Progress in Photovoltaics, vol. 8, no. 5, pp. 473487, 2000.
[6] S. R. Wenham, J. Zhao, X. Dai, A. Wang, and M. A. Green, "Surface passivation in high efficiency silicon solar cells," Solar Energy Materials and Solar Cells, vol. 65, no. 1, pp. 377-384, 2001.

[7] A. G. Aberle, S. Glunz, and W. Warta, "Field effect passivation of high efficiency silicon solar cells," Solar Energy Materials and Solar Cells, vol. 29, no. 2, pp. 175-182, 1993.

[8] A. G. Aberle, S. W. Glunz, A. W. Stephens, and M. A. Green, "High-efficiency silicon solar cells: $\mathrm{Si} / \mathrm{SiO} 2$ interface parameters and their impact on device performance," Progress in Photovoltaics, vol. 2, no. 4, pp. 265-273, 1994.

[9] W. D. Eades and R. M. Swanson, "Calculation of surface generation and recombination velocities at the $\mathrm{Si}-\mathrm{SiO} 2$ interface," Journal of Applied Physics, vol. 58, no. 11, pp. 4267-4276, 1985.

[10] B. J. O'Sullivan, P. K. Hurley, C. Leveugle, and J. H. Das, " $\mathrm{Si}(100)-\mathrm{SiO}_{2}$ interface properties following rapid thermal processing," Journal of Applied Physics, vol. 89, no. 7, pp. 38113820, 2001.

[11] T. Watanabe, K. Tatsumura, and I. Ohdomari, "New linearparabolic rate equation for thermal oxidation of silicon," Physical Review Letters, vol. 96, Article ID 196102, p. 4, 2006.

[12] S. De Wolf, G. Agostinelli, G. Beaucarne, and P. Vitanov, "Influence of stoichiometry of direct plasma-enhanced chemical vapor deposited SiN films and silicon substrate surface roughness on surface passivation," Journal of Applied Physics, vol. 97, no. 6, Article ID 063303, pp. 1-8, 2005.

[13] M. W. M. van Cleef, F. A. Rubinelli, R. Rizzoli, R. Pinghini, R. E. I. Schropp, and W. F. van der Weg, "Amorphous silicon carbide/crystalline silicon heterojunction solar cells: a comprehensive study of the photocarrier collection," Japanese Journal of Applied Physics, vol. 37, no. 7, pp. 3926-3932, 1998. 


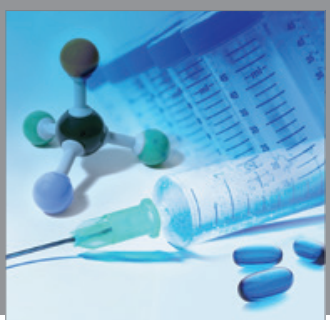

International Journal of

Medicinal Chemistry

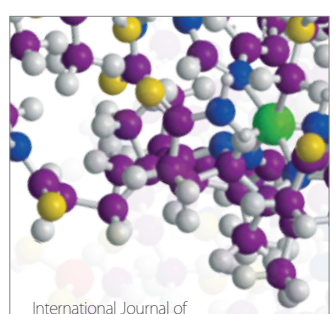

Carbohydrate Chemistry

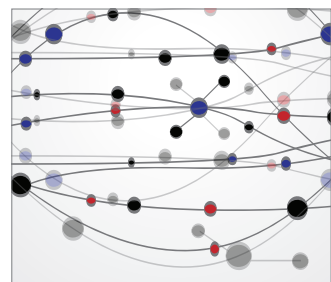

The Scientific World Journal
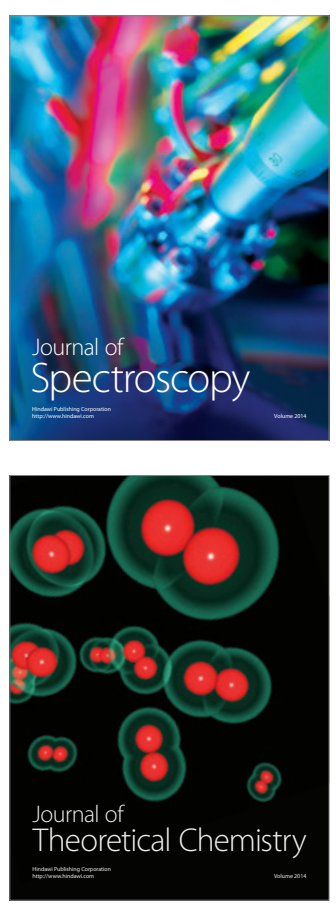
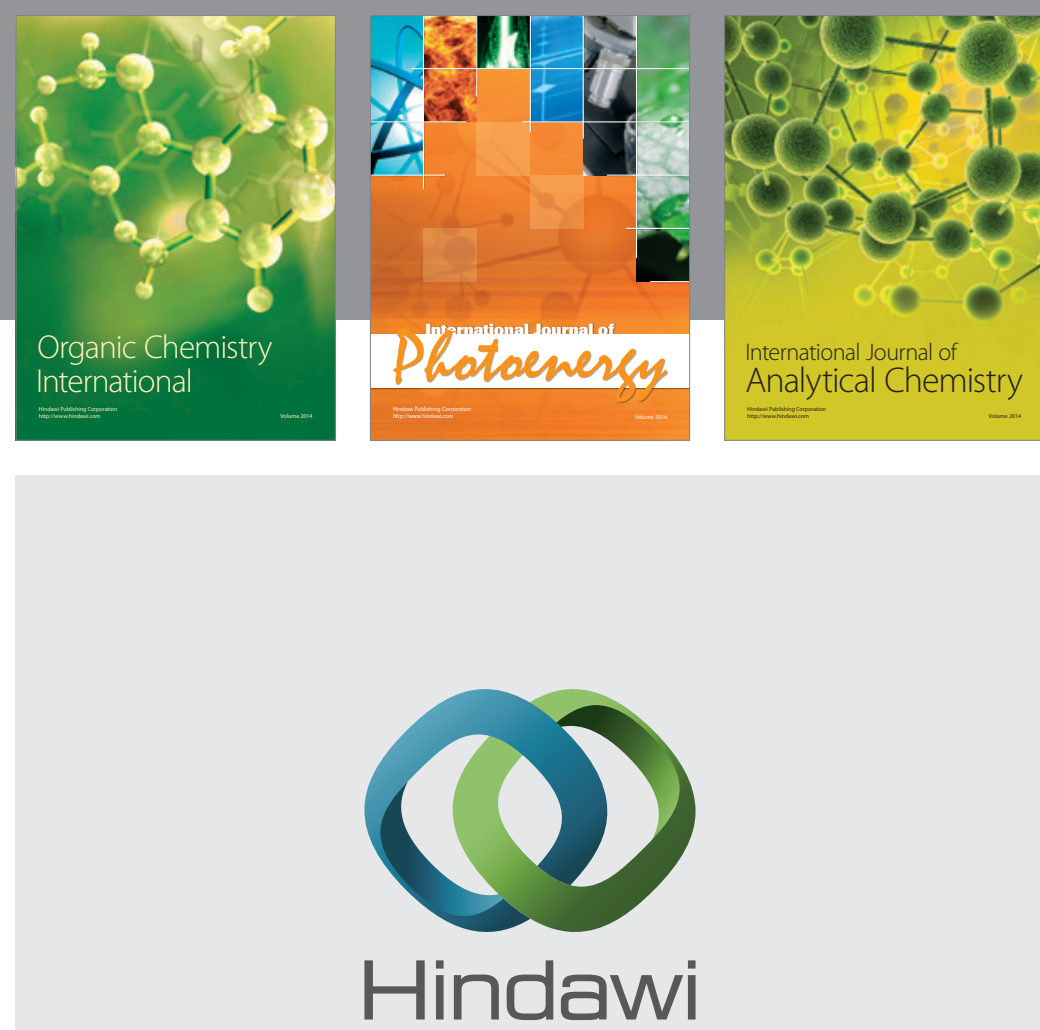

Submit your manuscripts at

http://www.hindawi.com
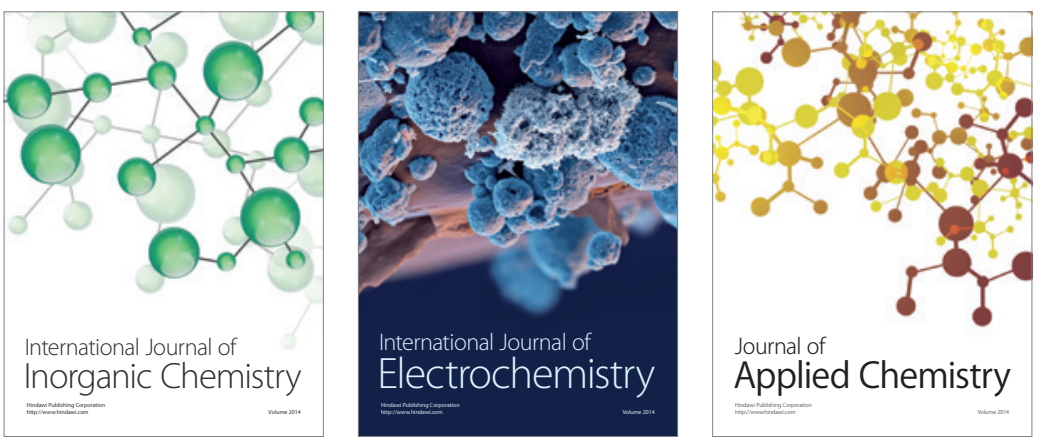

Journal of

Applied Chemistry
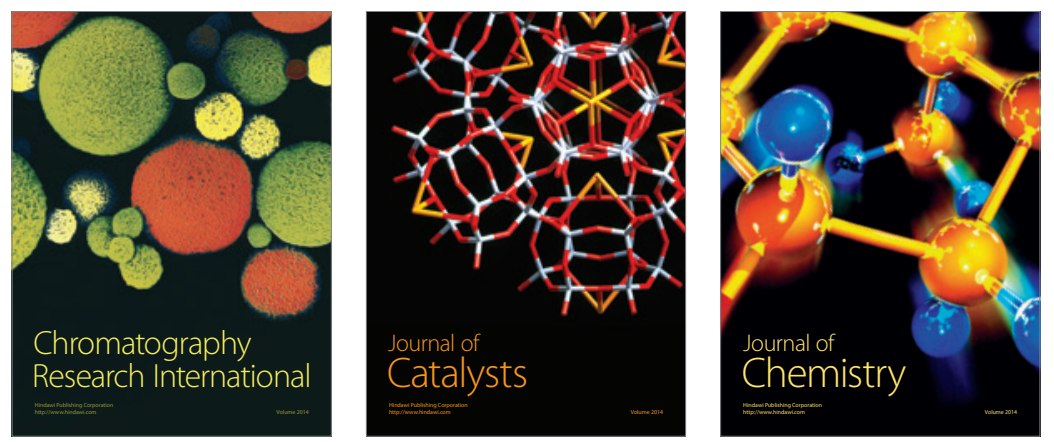
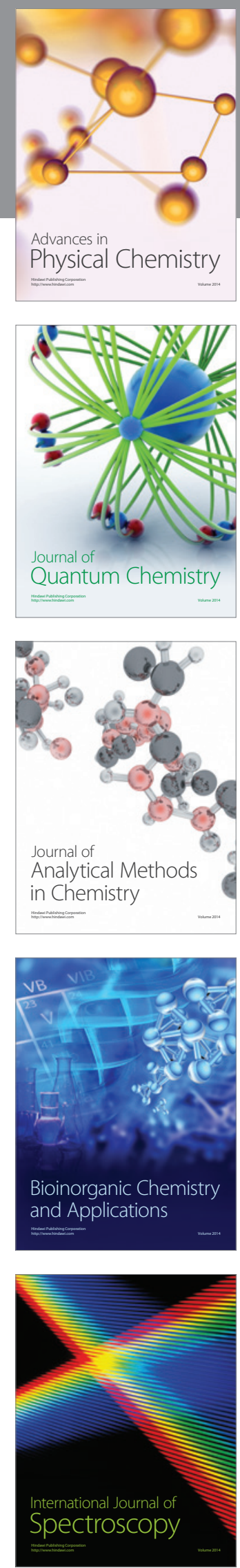